\title{
The good, the bad and the outliers: automated detection of errors and outliers from groundwater hydrographs
}

\author{
Tim. J. Peterson ${ }^{1^{*}}$, Andrew W Western ${ }^{1}$ and Xiang Cheng ${ }^{2}$
}

*timjp@unimelb.edu.au

1. Department of Infrastructure Engineering, The University of Melbourne, Victoria, Australia

2. Department of Economic Development, Jobs, Transport and Resources, Victoria, Australia

\section{Abstract}

Suspicious groundwater-level observations are common and can arise for many reasons ranging from an unforeseen biophysical process to bore failure and data management errors. Unforeseen observations may provide valuable insights that challenge existing expectations and can be deemed outliers, while monitoring and data handling failures can be deemed errors, and, if ignored, may compromise trend analysis and groundwater model calibration. Ideally, outliers and errors should be identified but to date this has been a subjective process that is not reproducible and is inefficient. This paper presents an approach to objectively and efficiently identify multiple types of errors and outliers.

The approach requires only the observed groundwater hydrograph, requires no particular consideration of the hydrogeology, the drivers (e.g. pumping) or the monitoring frequency, and is freely available in the HydroSight toolbox. Herein, the algorithms and time-series model are detailed 1 and applied to four observation bores with varying dynamics. The detection of outliers was most reliable when the observation data were acquired quarterly or more frequently. Outlier detection 3 where the groundwater-level variance is non-stationary or the absolute trend increases rapidly was 
24 more challenging, with the former likely to result in an under-estimation of the number of outliers and

25 the latter an over-estimation in the number of outliers.

26

27 Keywords: Groundwater monitoring, Statistical modeling

28

\section{Introduction}

30 Unreliable groundwater level observations can arise from observation bore failures (e.g. bore collapse

31 or bore flooded) and data management (e.g. recording in the field, entry into databases) and can be

32 deemed errors. Such errors are often not recorded by quality codes, in which case the observed

33 hydrograph contains spurious observations that may compromise trend analysis and model

34 calibration, especially when using a least-squares objective function which will give undue weight to

35 groundwater levels appearing as spikes. Outliers can also arise when an observation does not

36 conform to our expectations of the aquifer and, while further examination may identify them as errors,

37 they may also offer insights to the aquifer that should not be overlooked. Ideally such errors and

38 outliers should be identified and considered for omission from analysis. However, the lack of

39 appropriate automated methods results in errors and outliers either being ignored or a reliance on

40 manual subjective inspection of the data, a process which is not reproducible, inefficient when

41 multiple parties analyze the same data and impossible for analysis of large (e.g. national) datasets.

42 This paper presents an approach to objectively and efficiently identify multiple types of spurious

43 observations, with the implausible deemed errors and the plausible but unusual deemed outliers. The

44 approach requires only the observed groundwater hydrograph and requires no consideration of the

45 local hydrogeology, meteorology or other drivers (e.g. pumping).

46 The identification of erroneous groundwater level observations has only received modest attention to

47 date. Tremblay et al. [2015] identified outliers using a simple threshold maximum deviation from the

48 mean water level, while Li et al. [2016] identified outliers as those points more than three standard

49 deviations away from a moving-window smoothed hydrograph. More recently Berendrecht and van

50 Geer [2016] presented a multi-bore groundwater time-series approach that was shown capable of

51 graphically identifying single outliers when neighboring bores where frequently monitored. Outside 
52 hydrogeology, time-series outlier detection methods have been investigated for many decades. For

53 time-series outlier detection, statistical time-series modeling has been the predominant approach.

54 Four types of outliers have been characterized, with approaches developed for each. Following Chan

55 [1995], these are additive outliers (AO), innovational outliers (IO), level shifts (LS) and temporary

56 changes (TC).

57 An AO affects only the observation(s) in question, appearing as a spike in groundwater level for one

58 or more isolated observations. IOs are a more challenging scenario. With IOs, serial correlation

59 causes the outlier to affect all subsequent observations, and in this application could result from an

60 obstruction to the bore that influences all future observations. Similarly, LS affects all subsequent

61 observations but by a step-change in the system rather than from the serial correlation, and in this

62 application might result from a shift in the measurement datum. Lastly, TC affects subsequent

63 observations but, unlike IOs, the impact decays with time. Stepping back from this typology, outliers

64 can be deemed as a subset of anomalies; that is, unusual observations that may be erroneous or may

65 provide clues of new processes that warrant investigation, not removal [Chandola et al. 2009]. The

66 automated removal of hydrograph errors and outliers risks overlooking potentially important clues

67 (e.g. a bypass recharge event appearing as a spike), and it is very difficult to distinguish between

68 errors and true but unusual system responses. In this paper, the outliers identified cannot be

69 objectively separated into these two groups and, in the end, the outliers may be valuable clues

70 omitted from further consideration.

71 Despite these caveats, AOs are likely to be the most common type of outliers in groundwater

72 hydrographs and are the focus herein. However, temporary LSs can also appear, in the authors'

73 experience, as periods of constant head offset arising from data management failures or the water

74 level declining below the screen. The paper therefore also presents a series of hydrogeologically

75 relevant heuristics to identify LS errors, and other spurious observations, after which AOs are

76 identified using a time-series modeling approach. It is however important to remain mindful that more

77 challenging types of anomalies, e.g. IO and TC, are unlikely to be detected by the presented

78 approach and their prevalence may increase with increased adoption of automated sensors. 
79 The basis of the $\mathrm{AO}$ detection is a comparison between individual observed data points and a time-

80 series model fitted to the data. For example, Battaglia and Orfei [2005] used a nonlinear time-series

81 model to identify the timing of outliers and their amplitude from regularly sampled nonlinear data.

82 They found that the detection of outliers required iterative application of the model to over-come the

83 challenge of outliers remaining within the dataset affecting the parameters of the time-series model

84 used to identify outliers. In this paper a similar iterative approach was found to be important in outlier

85 detection. A further challenge, and one not known to be addressed in the outlier detection literature, is

86 that groundwater hydrographs very rarely have a regular monitoring time-step, are likely to be first-

87 order and second-order non-stationary (i.e. mean and variance change with time) and, with aquifers

88 being an open system, the structure of the time-series model and drivers are inherently unknown.

89 Furthermore, the drivers causing the observed groundwater level time-series may not be known, nor

90 observed, and they may vary over time. With these challenges, it is not surprising that an automated

91 outlier detection approach has not yet been developed for groundwater hydrographs. Advances in

92 groundwater time-series modeling present a means to account for irregular observation time-steps

93 and serially correlated residuals [von Asmuth \& Bierkens 2005] within a numerically robust approach

94 [Peterson \& Western 2014]. In the following section, an algorithm is presented for detecting common

95 errors and then the aforementioned research is drawn upon to present an algorithm for detecting

96 outliers. Both have been developed without limitations on the type of aquifer and monitoring regime.

97 Four applications are presented, which are then discussed.

\section{Methods}

99 This section presents an overview of the approach for automatic identification and removal of

100 erroneous and outlier observations. The main algorithm is in Section 'Outlier detection algorithm'. It

101 first uses heuristics to identify and remove physically implausible observation (e.g. observations below

102 the screen or before the bore construction date), which herein are considered to be errors. Next, the

103 main algorithm calls the sub-algorithm to identify plausible but unusual observations, which are

104 considered to be outliers in this paper. 
105 The approach is available as a graphical module within the HydroSight toolbox (http://peterson-tim-

106 j.github.io/HydroSight/; Peterson et al. 2017), as is the source code (see files

107 doDataQualityAnalysis.m, outlierDetection.m and ExpSmooth.m for details of the error detection,

108 outlier detection and exponential smoothing respectively).

\subsection{Error and outlier detection algorithm}

110 The algorithm for the automated identification and removal of erroneous and outlier observations is

111 detailed as Algorithm 1, in Figure 1. The required inputs are the groundwater hydrograph to be

112 analyzed (observation date-time, water level elevation and ideally with known errors already removed;

113 e.g. quality codes denoting, say, a collapsed bore) and eight user-set parameters controlling the error

114 and outlier analysis; four of these are based on the physical attributes of the bore, and guidance is

115 given for the remaining four in Section 'Algorithm Application'.

116 The algorithm sequentially applies a series of heuristics to identify errors, with the order of each

117 chosen to maximize its effectiveness. The first set of heuristics analyze all observations for plausible

118 observation dates (i.e. after the construction date and prior to the minimum of the bore termination

119 data and the current date), duplicate observations for a single time-point, and plausible heads (i.e.

120 above the elevation of the bottom of the screen and below the top-of-casing elevation). Next, the

121 sequence of remaining observations are analyzed for errors [see lines 14-42 of Algorithm 1 (Figure

122 1)]. This involves searching for periods of implausible absolute change in head [see lines 14-18],

123 followed by periods of constant head exceeding a user defined duration [see lines 22-42]. Lastly, the

124 remaining observations are assessed for outliers [see lines 43-47 and sec. 'Outlier detection

125 algorithm].

126 [Fig 1 goes here.]

127 Clearly not all of the above heuristics are applicable to all observation bores. For example, the check

128 for the water level being below the top-of-casing would be inappropriate for artesian bores. Likewise, checking for duplicate observations may be inappropriate when automatic pressure transducers are 
checked against manual observations. The selected heuristics should therefore be chosen to reflect the physical conditions of the study area. HydroSight allows selection of each individual heuristic.

\subsection{Outlier detection algorithm}

The algorithm for outlier detection is given as Algorithm 2, in Figure 2. Central to the algorithm is the construction of a double exponential smoothing time-series model and its fit to the observed hydrograph using the SP-UCI [Chu et al. 2011] global calibration scheme (Section 'Outlier detection time-series model'). After an outlier is identified and removed, the time-series model is re-calibrated and, while computationally demanding, it was found necessary to identify sequences of outliers and is consistent with other outlier detection approaches [Battaglia \& Orfei 2005].

Conceptuality, the key steps of the outlier detection algorithm, starting from observation $i=1$, are as follows:

1. Calibrate the time series model using the remaining data from the error detection process;

2. Removing observation $i$ from the hydrograph and run the time-series model using the remaining data;

3. Calculate the model residuals and, to minimize the impacts of remaining outliers other than observation $i$, remove the minimum and maximum residual values from the vector or residuals (note: all minimum and maximum residual values are removed, and at least two values are always removed);

4. Estimate the hydrograph noise, $\sigma_{t}$, at observation $i$ using Eq. 15;

5. Predict observation $i$ water level using the calibrated model parameters and Eq. 3;

6. Calculate the error in the prediction. If the error is greater than $\eta \times \sigma_{t}(\eta$ is a user set number of noise standard deviations, herein set to 4), then identify the observation as an outlier, remove it and go to step 7. Else, increment $i$ and repeat steps 2-6 for all observations. 
7. Set $i=1$ and repeat steps $1-6$ until no outlier is detected.

154 In assessing if an observation is an outlier (step 6 above), the residuals were assumed independent

155 and identically distributed (iid). With $\eta$ set to four and assuming normality of the residuals, the

156 probability of an observation being four noise standard deviations away from the time-series model

157 prediction would be $<6.3 e-05$. Assuming the time-series model is adequate and the residuals are iid

158 and normal, there is a low probability of incorrectly removing non-outliers. Given the simplicity of the

159 model (described in the next section), it may produce residuals that are serially correlated, in which

160 case the above probabilities should be considered as a lower limit.

$161 \quad$ [Fig 2 goes here.]

\subsection{Outlier detection time-series model}

163 Smoothing groundwater hydrographs presents a number of challenges. Specifically, groundwater

164 hydrographs are often irregularly sampled and are influenced by temporally varying external drivers,

165 such as climate, pumping or land-use change, that produce water level fluctuations on timescales

166 ranging from daily to decadal or longer. Combined, these challenges result in an irregularly sampled

167 first and second order non-stationary time-series not suitable for analysis with standard exponential

168 smoothing techniques. An alternative is damped double exponential smoothing for irregular data

169 [Cipra 2006]. The approach smooths both a damped trend and the component not explained by the

170 trend. Combined with Wright's method for irregularly spaced data, a smoothing algorithm can be

171 derived that is applicable to groundwater hydrographs. From Cipra [2006], the smoothed estimate at

172 time $t_{n}, S_{t_{n}}$, is estimated from the weighted sum of the current observation, $y_{t_{n}}$ (i.e. the observed

173 groundwater level), the smoothed estimate from the prior time step, $S_{t_{n-1}}$, and the damped trend,

$174 T_{t_{n-1}}:$

$175 S_{t_{n}}=\alpha_{t_{n}} \times y_{t_{n}}+\left(1-\alpha_{t_{n}}\right)\left(S_{t_{n-1}}+\sum_{i=1}^{t_{n}-t_{n-1}} \varphi^{i} T_{t_{n-1}}\right)$

Eq. 1

176 where $\alpha_{t_{n-1}}$ is a time-varying smoothing coefficient and the sum term dampens the prior trend $T_{t_{n-1}}$

177 using a damping coefficient $(0<\varphi<1)$ to the power of the duration from $t_{n-1}$ to $t_{n}$, causing the trend to

178 decay to zero over time. Thus the trend at the current time point is: 
180 where $\gamma_{t_{n-1}}$ is a time-varying smoothing coefficient. The forecast, required at line 12 of Algorithm 2

181 (Fig 2), is calculated as:

$182 \widehat{y_{t_{n+k}}}=S_{t_{n}}+\sum_{i=1}^{k} \varphi^{i} T_{t_{n-1}}, k \geq 0$

Eq. 3

183 where $k$ is the number of time-steps forecast. Additionally, the two time-varying smoothing

184 coefficients, $\alpha_{t_{n-1}}$ and $\gamma_{t_{n-1}}$, are estimated as follows:

$185 \quad \alpha_{t_{n}}=\frac{\alpha_{t_{n-1}}}{(1-\alpha)^{t_{n}-t_{n-1}+\alpha_{t_{n-1}}}}$

Eq. 4

$\gamma_{t_{n}}=\frac{\gamma_{t_{n-1}}}{(1-\gamma)^{t_{n}-t_{n-1}}+\gamma_{t_{n-1}}}$

186 where the initial values, $\alpha_{t_{0}}$ and $\gamma_{t_{0}}$, are approximated from the mean observation frequency, $q$, and

187 input parameters $\alpha$ and $\gamma$ :

$188 \alpha_{t_{0}}=1-(1-\alpha)^{q}$

Eq. 5

$189 \gamma_{t_{0}}=1-(1-\gamma)^{q}$

Eq. 6

$190 \quad q=\frac{1}{n} \sum_{i=1}^{n-1}\left(t_{n+1}-t_{n}\right)$

191 Departing from Cipra [2006], the initial values for $S_{t_{0}}$ and $T_{t_{0}}$ were estimated using a smoothing spline

192 (see Matlab csaps function) fit to the entire observation record, from which the initial spline head and 193 slope are extracted. Additionally, inclusion of the damping coefficient $(0<\varphi<1)$ was found to add

194 little benefit at the cost of increased calibration demand. Therefore, it was removed by replacing the

195 sum terms in Eq. 1, 2 and 3 with the time step, $t_{n}-t_{n-1}$, and the term $\varphi^{\left(t_{n}-t_{n-1}\right)}$ in Eq. 2 by 1 . The

196 final equations used in the approach were:

$197 S_{t_{n}}=\alpha_{t_{n}} \times y_{t_{n}}+\left(1-\alpha_{t_{n}}\right)\left(S_{t_{n-1}}+\left(t_{n}-t_{n-1}\right) T_{t_{n-1}}\right)$

$198 T_{t_{n}}=\frac{\gamma_{t_{n}}}{t_{n}-t_{n-1}}\left(S_{t_{n}}-S_{t_{n-1}}\right)+\left(1-\gamma_{t_{n}}\right) T_{t_{n-1}}$

$199 \widehat{y_{t_{n+k}}}=S_{t_{n}}+\left(t_{n}-t_{n-1}\right) T_{t_{n-1}}, k \geq 0$

200 The application of the exponential smoothing model to a hydrograph requires two parameters, $\alpha$ and

$201 \gamma$. Considering the natural variability in groundwater hydrographs and monitoring regimes, it is appropriate that the parameters be estimated for each hydrograph and that this be objective and 
203 automated. This was achieved using a variant of the von Asmuth and Bierkens [2005] objective

204 function, which accounts for the serial correlation between the residuals by using the innovations (i.e.

205 the change in the model residuals over irregular time-steps) rather than the model residuals

206 themselves, and then weights the innovations by the time-step; which can be irregular. Below, the

207 relevant equations from the modifications to the von Asmuth and Bierkens [2005] by Peterson and

208 Western [2014] are reproduced.

209 The residuals at a time point were calculated as:

$210 \varepsilon_{t}=h_{t}-h_{t}^{*}-d$

Eq. 11

211 where $\varepsilon_{t}[\mathrm{~L}]$ is the residual at time $t ; h_{t}[\mathrm{~L}]$ is the observed groundwater elevation at time $t ; h_{t}^{*}[\mathrm{~L}]$ is the

212 smoothed groundwater level at time $t$; and $d[\mathrm{~L}]$ is a drainage elevation constant. In modeling the

213 groundwater level, the mean of the residuals was assumed to equal zero and this allowed estimation

214 of the drainage elevation constant:

$215 d=\bar{h}-\bar{h}_{t}^{*}$

Eq. 12

216 where $\bar{h}[\mathrm{~L}]$ is the arithmetic mean observed groundwater level over the calibration period; and $\bar{h}_{t}^{*}[\mathrm{~L}]$ is

217 the arithmetic mean smoothed estimate, $h_{t}^{*}[L]$, over the calibration period. Use of the mean levels

218 does however assume that the observed hydrograph has a fairly regular monitoring frequency. If the

219 hydrograph has long periods of, say, seasonal observations followed by a period of daily observations

220 then the arithmetic mean may be overly weighted toward the period of daily observations. Care

221 should therefore be taken in application of the approach to hydrographs having highly varying

222 observation frequencies.

223 Next, the innovations, $v_{t}[L]$, over an irregular time step were defined by assuming an exponential

224 decay of the residuals:

$225 v_{t}=\varepsilon_{t}-\varepsilon_{t-\Delta t} e^{-\beta \Delta t}$

226 where $\varepsilon_{t-\Delta t}[\mathrm{~L}]$ is the residual at the previous groundwater observation time; $\Delta t[\mathrm{~T}]$ is the time step to

227 the previous groundwater observation; and $\beta[1 / T]$ is a parameter defining the decay rate of the

228 residuals. The standard deviation of the model noise, $\sigma_{n}[L]$, is then estimated from the residuals:

$229 \quad \sigma_{n}=\sqrt{\frac{1}{n-1} \sum_{i=1}^{n-1}\left(\frac{v_{i}^{2}}{1-\exp \left(-2 \beta \Delta t_{i}\right)}\right)}$

Eq. 14 
230 In this application, the noise needs to be time-dependent to account for the varying time separation

231 between the observation being assessed as an outlier and the preceding observation. To estimate the

232 time-dependent noise, Eq. A7 in von Asmuth and Bierkens [2005] was extended as follows using the

233 arithmetic mean of the innovations:

$234 \quad \sigma_{t}=\sqrt{\frac{\frac{1}{n-1} \sum_{i=1}^{n-1} v_{i}^{2}}{1-\exp (-2 \beta \Delta t)}}$

235 where in this instance $\Delta t[T]$ is the time separation between the time-point, $t$, at which an estimate is

236 required and the time at the proceeding observation. Using Eq. 10 above, von Asmuth and Bierkens

237 [2005] derived an objective function used to optimize all model parameters, including the noise

238 parameter $\beta$. To increase numerical stability, Peterson and Western [2014] modified it to the following:

$239 \quad \chi^{2}=\sum_{i=1}^{n-1} \frac{\exp \left(\frac{1}{n-1} \sum_{j=1}^{n-1}\left[\ln \left(1-\exp \left(-2 \widehat{\beta} \Delta t_{i}\right)\right)\right]\right)}{1-\exp \left(-2 \hat{\beta} \Delta t_{j}\right)} v^{2}\left(t_{j}, \hat{\beta}\right)$

240 where $\hat{\beta}$ is the anti-log transform of $\beta$ and $\hat{\beta}=10^{\beta}$. To improve the performance of the global

241 calibration scheme, SP-UCl, all parameters should be encoded to have similar sensitivity to each

242 other. To achieve this, all three calibrated parameters were $\log _{10}$ transformed.

\subsection{Algorithm Application}

244 Four unconfined observation bores where selected to demonstrate the error and outlier detection 245 algorithms (Table 1). The bores are located in Victoria, Australia, and were selected to illustrate the 246 performance of the algorithms under a range of scenarios. Specifically, the bores were chosen with 247 periods of constant head (bore 27174), approximately linear trends (bore 27174), varying trends (bore 248 99), possible sequential outliers (bores 27174 and WRK957283) and periods of high and low variance 249 (bore 1101). In each application of the algorithms, the minimum constant head duration, $t_{\text {const }}$, was 90 250 days, the minimum number of observations in the constant head period, $n_{\text {const }}$, was three, the number of noise standard deviations denoting an outlier, $\eta$, was four and the maximum plausible absolute rate of change, $r_{\max }$, was set to $10 \mathrm{~m} /$ day; future applications could adopt a site specific value derived from the within-season water level variability. All other user-set parameters were taken from Table 1. 
257 The outlier detection algorithm is clearly the most significant aspect of the approach. To further

258 explore its behavior, the application to the four bores was repeated using (i) water level data re-

259 sampled to lower frequencies and (ii) a range of values for $\eta$. For the re-sampling, the water level data

260 were re-sampled to 49 time-steps having a minimum frequency of 28 days up to 364 days (7-day

261 increments). Additionally, the identified outliers from the complete data were inserted into each re-

262 sampled data set to allow comparison of the results. To analyze the results, the following measures

263 were extracted for each bore and time-step: coefficient of efficiency, providing a measure of the model

264 fit to the overall time-series; each of the three time-series model parameters; the standard deviation of

265 the noise (Eq. 14) and the exponential model variogram range of the innovation, providing a measure

266 of the serial correlation; the number of outliers detected; and the number of the outliers detected from

267 the complete data that were identified using each re-sampled data set.

268 To provide some indication of the computational demands of the error and outlier detection, the run-

269 time for the aforementioned analysis was estimated at $\tau=2.79 m+6.51\left(r^{2}=0.793\right)$ where $\tau$ is the

270 run-time in seconds and $m$ is the number of outliers detected (note, the analysis was undertaken

271 using a 6 -Core $3.6 \mathrm{GHz}$ i7-6850 PC). For the complete data, analysis of each of the four bores

272 required a run-time mean and standard deviation of $33 \mathrm{~s}$ and $28 \mathrm{~s}$ respectively.

273 Lastly, to investigate the sensitivity to $\eta$ the analysis was repeated using the complete data and

274 values of $\eta$ from 2 to 6 at 0.25 increments. The results were then summarized by extracting the

275 number of outliers detected and the number of those outliers detected from when $\eta=4$.

$276 \quad 3$. Results

277 Fig. 3 summarizes application of the error and outlier detection algorithm to the four selected bores.

278 Fig. 3a shows a hydrograph having an approximately linear trend and irregular sampling, with monthly 279 samples pre-2007 and annual samples thereafter. Two periods of constant head were identified by 280 Algorithm 1 and eight outliers by Algorithm 2. Most notably, a sequence of outliers with different head 281 values was detected in 1993 and another sequence, but with similar head values, was detected in 282 2006. Fig. 3b shows a hydrograph with approximately regular monthly monitoring but with more 

sequential with one non-outlier between each, despite appearing to be a sequence of outliers.

Fig. 3c shows a hydrograph again having complex trends but also a temporal trend in the variance, with the within-year head variance increasing following the late 1980s; the cause of this is unknown but it may be due to the commencement of irrigation and/or groundwater pumping within the region. The fitted noise is effectively an average of the two periods, with the noise in the earlier period overestimated and that in the latter period under-estimated. No outliers were identified in either period. This example illustrates a limitation of the outlier detection approach in that it assumes a stationary variance. Outliers within periods of lower variance would need to be quite extreme to be detected.

Lastly, Fig. 3d shows a hydrograph having an initial inter-annual period of rapid water level rise followed by a period of relatively constant water level. Nine outliers were identified, but inspection of the hydrograph suggests some of those identified in the 1980 s and 1990s are questionable. To investigate, the insert to Fig. 3d shows an iteration of the Algorithm 2 while-loop analyzing the fourth outlier. It shows the trimmed observed hydrograph with the point under consideration omitted and the fitted smoothed hydrograph. To assess the observation (denoted by a white circle), the time-series model is first used to forecast the point to assess (denoted by a black square). If the observed point is, in this example, greater than four times the standard deviation of the noise from the forecast point then it is deemed an outlier. From Eq. 3, the forecast is derived from the sum of the weighted previous observation and the trend at the previous observation. The point to be assessed is not used in the trend estimation and, as shown by the insert, when there is a rapid water level change (relative to the recent inter-annual water level variance) the forecast may significantly under or over estimate the observed water level. In Fig. 3d, this resulted in the questionable identification of 6 observations as outliers (2 in 1981, 3 in 1987, 1 in 2004).

\section{$306 \quad$ [Figure 3 here.]}

307 To explore the performance of the outlier detection algorithm as the observation frequency changes,

308 Fig. 4 shows results from re-sampled water level data with maximum time-steps of 28 up to 364 days

309 (7-day increments), with that at a zero time-step showing the results from the complete data (see 
310 Table 1 for details of the complete data). Fig. 4a shows that the coefficient of efficiency for the fit

311 between the time-series model and the re-sampled water level data, with 1 denoting a perfect fit and

$312<0$ denoting a fit worse than from using the mean water level. It shows that for 3 of the 4 bores the fit

313 was very good when the sample time-step is $<100$ days. For bore 1101 the fit was around 0.5 , and

314 this is most likely due to the water level variance changing over time. Considering the purpose of the

315 time-series model is to produce a smoothened head for estimation of the noise, and not an excellent

316 fit to the hydrograph, the more relevant aspect from Fig. $4 \mathrm{a}$ is that the fit is stable at all bores up to a

317 time-step of 100 to 200 days. Fig. 4b-d show that the corresponding model parameters were more

318 variable but do show a similar change at about 100 days, and most notably so in Fig. 4b and Fig. 4c.

319 Fig. 4e shows the estimated residual noise standard deviation after all identified errors and outliers

320 are removed. Similar to the proceeding plots, it shows a notable increase between 100 and 200 days

321 for bores WRK957283 and 99 and slightly so for 1101 . At WRK957283 the noise increased by over

322 an order of magnitude, and also at 1101 but only beyond 250 days observation time-step. Fig. $4 \mathrm{f}$

323 shows a similar increase in the correlation of the innovations beyond 70 days to a variogram range of

324 above 200 days. Interestingly, below 70 days the variogram range was between 14 and 60 days for 3

325 bores. This indicates that the innovations remained serially correlated (note, given the exponential

326 variogram, the variogram is at $95 \%$ of the sill for a time-step 3 times the range - that is, some

327 correlation remains at up to 180 days). The innovations are therefore not iid and hence the indicative

328 probabilities for detection of outliers (sec. 'Outlier detection algorithm') should be treated with caution.

329 Fig. $4 \mathrm{e}$ and $\mathrm{f}$ do however suggest that for seasonal or greater observation frequencies, the time-series

330 model produces plausible estimates of the noise and innovations with relatively low serial correlation.

331 To investigate the resulting outlier detection, Fig $4 \mathrm{~g}$ shows the number of outliers detected. It shows

332 that at each bore the number of outliers first fluctuates by 1-2 points with the sample time step, and

333 beyond approximately 100 days, the fluctuations become larger, especially at 27174 and

334 WRK957283. Fig. 4h shows the number of outliers from the re-sampled data that correspond with

335 outliers from the complete data. Comparing Figs $4 \mathrm{~g}$ and $4 \mathrm{~h}$, shows that when outliers are detected all

336 but 1-2 of them are the outliers detected from the non re-sampled data. This suggests that, while the

337 probability of detecting an outlier decreases as the observation frequency declines, the outliers that 
338

339

340 [Figure 4 here.]

are detected are likely to be consistent with those that would have been detected had there been higher frequency data.

The other factor likely to heavily influence the performance of the outlier detection is the user set parameter for the number of noise standard deviations for an outlier, $\eta$. Fig. $5 a$ shows the change in

343 the number of outliers, relative to the number of outliers shown in Fig. 3, when $\eta$ is varied from 2.5 to 6. Unsurprisingly, it shows that the number of outliers is inversely related to $\eta$. More interestingly it shows that for each bore there exists a range for $\eta$ over which the number of outliers is constant. Clearly the outliers that are detected are likely to be those that are more extreme, but encouragingly the number of outliers does not decline to zero when $\eta=6$ for 3 of the four bores. Furthermore, Fig. $5 b$ shows that below the threshold value for $\eta$ the outliers that are detected include those that were detected in Fig. 3 at all but bore 99. Obviously the value of $\eta$ at which the number of outliers converges is likely to be dependent upon the hydrograph dynamics, but this threshold point for $\eta$ appears to provide a means for objectively setting $\eta$ and in doing so objectively identifying the more extreme outliers.

[Figure 5 here.]

\section{Discussion and Conclusion}

355 This paper presents applied algorithms for automated detection of erroneous and outlier groundwater 356 hydrograph observations. The algorithms detect a range of simple errors that can arise from issues 357 ranging from bore condition to the process of recording data in the field to inputting data to agency 358 databases. It was achieved using simple heuristics to remove implausible water level observations, 359 with the remaining observations being examined for outliers by iterative application of a calibrated 360 double-exponential smoothing time-series model. or assumptions of the aquifer characteristics (e.g. hydraulic properties) or drivers. The algorithms 
were demonstrated on four groundwater hydrographs with varying dynamics and, with the caveats from the 'Introduction', were found to be capable of detecting errors and outliers where their number and timing is unknown a priori, including where the outliers are sequential with varying or similar values. Objectively assessing whether the identified outliers are accurate or erroneous data points is however intrinsically problematic because the cause of each outlier is unknown and may arise from recording errors or unusual but real natural processes.

The forecasting aspect of the outlier detection has the implication that rapid water level changes (relative to the entire hydrograph) are more likely to be identified as an outlier. Preferential or flood recharge, and possibly rapid pumping recovery, would cause such a rapid water level rise, while significant groundwater pumping from a low transmissivity aquifer may cause a rapid decline. If few water level observations are made during such events then, from the analysis in Fig 4, the observations of the event are likely to be falsely detected as outliers. More generally, the analysis of sample frequency indicates that the detection of outliers becomes less reliable when the observations are less frequent than seasonal. The number of noise standard deviations, $\eta$, was shown to significantly influence the number of outliers detected and for each bore a range for $\eta$ was identified, within which the number of outliers was constant and often greater than zero. For an observation frequency less than quarterly, trials varying $\eta$ may improve the outlier estimation, but the interaction of observation frequency and $\eta$ remains an open question. Furthermore, both are likely to be influenced by the observation record length, which [van der Spek \& Bakker 2017] showed to be more influential on groundwater time-series model prediction uncertainty than the observation frequency, a finding which clearly has implications for the residual noise estimation and hence the outlier detection.

A more challenging scenario was the detection of outliers when the groundwater level variance changes, with false negative outliers being more likely during the periods of low variance and false positive outliers being more likely during the periods of high variance. These challenges, while speaking to the diversity of groundwater hydrographs and the ongoing mathematical challenges of outlier detection [Chandola et al. 2009], illustrate that some caution is required when applying the outlier detection approach and when considering if identified outliers should be omitted from subsequent analysis. For such challenges, each period of relatively uniform variance and trend could 
be individually analyzed for outliers. Alternatively, more numerically demanding approaches may be required that use forcing data. Transfer function noise models are the obvious choice for such an extension and to date they have been developed to account for climate driven processes [Yihdego \& Webb 2011; Peterson \& Western 2014], groundwater pumping [von Asmuth et al. 2008; Shapoori et al. 2015a,b,c] and surface water interactions [von Asmuth et al. 2008].

No automated method is however a replacement for local hydrogeological and hydrographic knowledge, and no matter the progress made in error and outlier detection, manual inspection of groundwater hydrographs is likely to remain a basic hydrogeological skill. While a numerical approach may identify an observation as an error or outlier, a decision will always be required whether to omit the point from subsequent analysis or to regard it as a valuable insight into unexpected aquifer behavior. For this reason, the implementation of the algorithms into the HydroSight toolbox (Peterson et al. 2017) allows the graphical manual editing of each type of error and outlier from each hydrograph. Coupled with the inbuilt summary statistics of the analysis, HydroSight offers an efficient, objective and reproducible means to analyze 1,000 s of observation bores and to prioritize those requiring manual inspection.

\section{Acknowledgements}

This research was funded by the Australian Research Council Linkage Project LP130100958 and funding partners - Bureau of Meteorology (Australia); Department of Environment, Land, Water and Planning (Vic., Australia); Department of Economic Development, Jobs, Transport and Resources (Vic., Australia); and Power and Water Corporation (N.T., Australia). The authors are grateful to Dr Elisabetta Carrara (Bureau of Meteorology) for her constructive input during the development of the algorithms. 
416

417 


\begin{tabular}{|c|c|c|c|c|c|c|c|c|}
\hline Bore ID & Lat. & Long. & $\begin{array}{c}\text { Construction } \\
\text { year }\end{array}$ & $\begin{array}{c}\text { Land } \\
\text { surface } \\
\text { elevation } \\
\text { (m AHD) }\end{array}$ & $\begin{array}{c}\text { Bore } \\
\text { depth } \\
(\mathrm{m})\end{array}$ & $\begin{array}{c}\text { No. of } \\
\text { observations }\end{array}$ & $\begin{array}{l}\text { Mean } \\
\text { time- } \\
\text { step } \\
\text { (days) }\end{array}$ & $\begin{array}{l}\text { St. dev } \\
\text { of time- } \\
\text { step } \\
\text { (days) }\end{array}$ \\
\hline 27174 & -34.13 & 141.07 & 1991 & 26.3 & 10 & 160 & 51 & 75 \\
\hline WRK957283 & -36.50 & 146.45 & 1998 & 169.1 & 14.94 & 155 & 37 & 25 \\
\hline 1101 & -35.93 & 145.67 & 1975 & 114.4 & 9.5 & 191 & 34 & 15 \\
\hline 99 & -36.38 & 145.07 & 1971 & 99.3183 & 13.4 & 404 & 37 & 24 \\
\hline
\end{tabular}

Table 1. Summary of the four unconfined groundwater observation bores selected to demonstrate the error and outlier detection algorithms. Note, AHD denotes Australian Height Datum. 
FIGURE CAPTIONS:

Fig 1 Outline of the groundwater hydrograph error and outlier detection - Algorithm 1. Variables are italic, vectors are bold italic, the scope for each For, If and Else term is defined by the indentation, and comments are denoted by $/ * \ldots * /$

Fig 2. Outline of the outlier detection algorithm - Algorithm 2. Variables are italic, vectors are bold italic, the scope for each For, If and Else term is defined by the indentation, and comments are denoted by $/{ }^{*} \ldots{ }^{*} /$

Fig. 3: Application of the error and outlier detection algorithms to four observation bores in Victoria, Australia. Each plot presents the smoothed head, the $5^{\text {th }}-95^{\text {th }}$ percentile envelope of noise $( \pm 1.68$ standard deviations), the identified errors and outliers and the final hydrograph with errors and outliers removed. Note, only (a) contained constant head errors and no outliers were detected in (c). The insert in (d) details the identification of the fourth outlier and challenges that can arise when the head rapidly rises or falls.

Fig. 4: Application of the error and outlier detection algorithms to the four bores from Fig. 3 using observations re-sampled to a minimum frequency of 28 days up to 364 days (7-day increments). Note, the results at an $x$ axis value of zero are those from the non re-sampled data. Also, the identified outliers from Fig. 3 were inserted into each re-sampled data set to allow comparison of the results. (a) shows the model fit after the removal of errors and outliers, expressed as the coefficient of efficiency, and (b,c,d) show the corresponding time-series model parameters. (e) shows the standard deviation of the model noise. (f) shows the serial correlation of the model innovations as given by the model variogram range. $(\mathrm{g})$ shows the number of outliers detected. (h) shows the number of outliers detected using the re-sampled data that correspond to those detected using the complete data.

Fig. 5 Application of the error and outlier detection algorithms to the four bores from Fig. 3 using values for the number of noise standard deviations, $\eta$, ranging from 2.5 to 6 . (a) shows the number of outliers detected. (b) shows the number of outliers detected within the non re-sampled data that were also detected using the re-sampled data. 


\section{References}

420 von Asmuth, J. R. and Bierkens, M. F. P. (2005). Modeling irregularly spaced residual series as a 421 continuous stochastic process, Water Resour. Res. 41 10.1029/2004WR003726.

422 von Asmuth, J. R.; Maas, K.; Bakker, M. and Petersen, J. (2008). Modeling time series of ground 423 water head fluctuations subjected to multiple stresses, Groundwater $46: 30-40$ 10.1111/j.1745424 6584.2007.00382.x.

425 Battaglia, F. and Orfei, L. (2005). Outlier Detection And Estimation In NonLinear Time Series., Journal 426 of Time Series Analysis $26: 107$.

427 Berendrecht, W. and van Geer, F. (2016). A dynamic factor modeling framework for analyzing 428 multiple groundwater head series simultaneously., Journal of Hydrology $536: 50$ - 60 .

429 Chan, W.-S. (1995). Understanding the effect of time series outliers on sample autocorrelations, Test $430 \quad 4: 179-186$ 10.1007/BF02563108.

431 Chandola, V.; Banerjee, A. and Kumar, V. (2009). Anomaly detection: a survey., ACM Computing 432 Surveys : 15 .

433 Chu, W.; Gao, X. and Sorooshian, S. (2011). A new evolutionary search strategy for global 434 optimization of high-dimensional problems, Information Sciences $181: 4909$ - 4927 435 http://dx.doi.org/10.1016/j.ins.2011.06.024.

436 Cipra, T. (2006). Exponential smoothing for irregular data., Applications of Mathematics : 597. 
437 Li, L.; Wen, Z. and Wang, Z. (2016). . In: Zhang, L.; Song, X. \& Wu, Y. (Ed.), Outlier Detection and 438 Correction During the Process of Groundwater Lever Monitoring Base on Pauta Criterion with Self439 learning and Smooth Processing, Springer Singapore.

440 Peterson T. J. and Western, A. W. (2014). Nonlinear time-series modeling of unconfined groundwater 441 head, Water Resour. Res. 50 : 8330-8355 10.1002/2013WR014800.

Peterson T. J.; Western, A. W. and Shapoori, V. (2017). http://peterson-tim-i.github.io/HydroSight/.

443 Shapoori, V.; Peterson, T.; Western, A. and Costelloe, J. (2015a). Estimating aquifer properties using 444 groundwater hydrograph modelling, Hydrological Processes 29 : 5424-5437 10.1002/hyp.10583.

445 Shapoori, V.; Peterson, T. J.; Western, A. W. and Costelloe, J. F. (2015c). Decomposing groundwater 446 head variations into meteorological and pumping components: a synthetic study, Hydrogeology 447 Journal 23 : 1431-1448 10.1007/s10040-015-1269-7.

448 Shapoori, V.; Peterson, T. J.; Western, A. W. and Costelloe, J. F. (2015b). Top-down groundwater 449 hydrograph time-series modeling for climate-pumping decomposition, Hydrogeology Journal $450 \quad 10.1007 / \mathrm{s} 10040-014-1223-0$.

451 van der Spek, J. E. and Bakker, M. (2017). The influence of the length of the calibration period and 452 observation frequency on predictive uncertainty in time series modeling of groundwater dynamics, 453 Water Resources Research 53 : 2294-2311 10.1002/2016WR019704.

454 Tremblay, Y.; Lemieux, J.-M.; Fortier, R.; Molson, J.; Therrien, R.; Therrien, P.; Comeau, G. and 455 Talbot Poulin, M.-C. (2015). Semi-automated filtering of data outliers to improve spatial analysis of 456 piezometric data., Hydrogeology Journal $23: 851$ - 868 .

457 Yihdego, Y. and Webb, J. (2011). Modeling of bore hydrographs to determine the impact of climate 458 and land-use change in a temperate subhumid region of southeastern Australia., Hydrogeology 459 Journal $19: 877$ - 887 10.1007/s10040-011-0726-1. 


\section{HJ-2017-4667 Chinese}

462

463 理想值、不理想值及异常值：地下水水位图中误差和异常值的自动检测

464 可疑的地下水位观测结果很常见，有多种原因可造成意料之外的生物物理过程、钻孔故障及资料管理误 465 差。意料之外的观测结果可提供宝贵的启示，这些启示挑战已有的期望值，可被认为是异常值，而监测 466 和数据处理故障可被认为是误差, 如果忽略不计, 这些异常值和误差可危害趋势分析和地下水模型校正 467 。理想的是, 异常值和误差应当辨别出来, 但到目前为止, 这一直是个凭经验的过程, 这个过程是不可 468 复制的, 也是低效的。本文介绍了一种客观、有效地辨别多种类型的误差和异常值的方法。该方法只需 469 要观测的地下水位图, 不需要特别考虑水文地质条件、驱动因素 (例如抽水) 或者监测频率, 在 Hydro 470 Sight工具箱免费获得。在此, 详述了算法和时间序列模型, 并应用到四个具有不同动力学的观测孔中 471 。当每个季度或者更频繁地需要观测数据时, 异常值的检测最可靠。地下水位变化非稳定或者绝对趋势 472 快速增加的地方, 异常值检测更具挑战, 前者可能导致异常值数量的低估, 后者可能导致异常值数量的 473 高估。 
476 HJ-2017-4667 Spanish

477 Lo bueno, lo malo y lo extraño: detección automatizada de errores y

478 valores atípicos de los hidrogramas de agua subterránea

4806 Resumen

481 Las observaciones sospechosas del nivel de agua subterránea son comunes y pueden surgir por

482 muchas razones que van desde un proceso biofísico imprevisto hasta errores por fallas en la

483 perforación o en el manejo de los datos. Las observaciones imprevistas pueden aportar valiosas

484 ideas que desafían las expectativas existentes y pueden considerarse valores atípicos, mientras que

485 las fallas en el monitoreo y en el manejo de datos pueden considerarse errores y, si se ignoran,

486 pueden comprometer el análisis de tendencias y la calibración del modelo de agua subterránea.

487 Idealmente, se deben identificar los valores atípicos y los errores, pero hasta la fecha esto ha sido un

488 proceso subjetivo que no es reproducible y es ineficiente. Este artículo presenta un enfoque para

489 identificar objetiva y eficientemente múltiples tipos de errores y valores atípicos. El enfoque sólo

490 requiere el hidrograma de agua subterránea observado, no requiere consideración especial de la

491 hidrogeología, de los impulsos (por ejemplo, el bombeo) o de la frecuencia de monitoreo, y está

492 libremente disponible en la caja de herramientas de HydroSight. Aquí, los algoritmos y el modelo de

493 serie temporal se detallan y se aplican a cuatro pozos de observación con variables dinámicas. La

494 detección de valores atípicos fue más confiable cuando los datos de observación se adquirieron

495 trimestralmente o con mayor frecuencia. La detección de valores atípicos en que la varianza del nivel

496 del agua subterránea no es estacionaria o la tendencia absoluta aumenta rápidamente era más

497 difícil, ya que la primera probablemente daría lugar a una subestimación del número de valores

498 atípicos y la última a una sobreestimación del número de valores atípicos.

499 
5017 HJ-2017-4667 Português

5028

5039 O bem, o mau e os dados discrepantes: detecção automática de erros e dados 504 discrepantes a partir de hidrogramas das águas subterrâneas

50510

$506 \quad 11$

50712 Resumo

50813 Observações suspeitas sobre o nível das águas subterrâneas são comuns e podem surgir por 509 diversas razões que vão desde um processo biofísico imprevisto até a falha no furo e erros de gerenciamento de dados. As observações imprevistas podem fornecer informações valiosas que

511 desafiam as expectativas existentes e podem ser considerados dados discrepantes, enquanto 0 monitoramento e as falhas no tratamento de dados podem ser considerados erros e, se

513 ignorados, podem comprometer a análise de tendências e a calibração de modelo de águas 514 subterrâneas. Idealmente, dados discrepantes e erros devem ser identificados, mas até agora 515 este tem sido um processo subjetivo que não é reprodutível e é ineficiente. Este artigo apresenta 516 uma abordagem objetiva e eficiente para identificar múltiplos tipos de erros e dados 517 discrepantes. A abordagem requer apenas o hidrograma de águas subterrâneas observado, não 518 requer nenhuma consideração particular da hidrogeologia, as forçantes (p.ex. bombeamento) ou 519 a frequência de monitoramento, e é disponível gratuitamente na caixa de ferramentas 520 HydroSight. Aqui, os algoritmos e modelos de séries temporais são detalhados e aplicados em 521 quatro furos de observação com diferentes dinâmicas. A detecção de dados discrepantes foi 522 mais confiável quando os dados de observação foram adquiridos trimestralmente ou mais 523 frequentemente. A detecção de dados discrepantes em que a variância do nível da água 524 subterrânea não é estacionária ou a tendência absoluta aumenta rapidamente foi mais 525 desafiadora, com a primeira provavelmente resultando em uma subestimação do número de 526 dados discrepantes e a última uma sobre-estimava no número de dados discrepantes. 


\section{HJ-2017-4667 French}

530 Les bonnes, les mauvaises et les aberrantes: détection automatisée des erreurs et des données aberrantes des hydrogrammes des eaux souterraines

\section{Résumé}

Les observations suspectes du niveau des eaux souterraines sont fréquentes et peuvent survenir

536 pour de nombreuses raisons, allant d'un processus biophysique imprévu aux défauts de forage et aux

537 erreurs de gestion de données. Les observations imprévues peuvent fournir de précieuses

538 informations qui remettent en questions les prévisions existantes et peuvent être considérées comme 539 des valeurs aberrantes, tandis que les défauts de suivi et de traitement des données peuvent être

540 considérés comme des erreurs, et, si ignorées, peuvent compromettre l'analyse des tendances et la

541 calibration des modèles hydrogéologiques. Idéalement, des valeurs aberrantes et des erreurs doivent

542 être identifiées, mais à ce jour il s'agit d'un processus subjectif qui n'est pas reproductible et qui est

543 inefficace. Cet article présente une approche permettant d'identifier de manière objective et efficaces

544 de multiples types d'erreurs et de valeurs aberrantes. L'approche ne nécessite que l'hydrogramme

545 des niveaux d'eaux souterraines observés, ne requiert aucune attention particulière concernant

546 l'hydrogéologie, des paramètres d'influence (par exemple les pompages) ou la fréquence du suivi, et

547 est disponible gratuitement dans la boîte à outils HydroSight. Dans ce cas, les algorithmes et les

548 modèles de séries chronologiques sont détaillés et appliqués à quatre piézomètres possédant des

549 dynamiques variées. La détection des valeurs aberrantes était la plus fiable lorsque les données

550 d'observation étaient acquises trimestriellement ou plus fréquemment. La détection des valeurs

551 aberrantes où la variance du niveau d'eaux souterraines est non stationnaire ou la tendance absolue

552 augmente rapidement était plus difficile, la première pouvant entraîner une sous-estimation du

553 nombre de valeurs aberrantes et la dernière une surestimation du nombre de valeurs aberrantes. 
555

556

557 
Line $\quad$ Data: Groundwater hydrograph head, $\boldsymbol{h}$, and time, $\boldsymbol{t}$, vector.

number Parameters: $\quad$ bore construction date, $t_{\min }[\mathrm{T}]$;

bore termination date, $t_{\max }[\mathrm{T}]$;

screening lower elevation, $h_{\min }[\mathrm{L}]$;

top of casing elevation, $h_{\max }[\mathrm{L}]$;

maximum plausible absolute rate of change, $r_{\max }\left[\mathrm{L} \mathrm{T}^{-1}\right]$;

minimum constant head duration, $t_{\text {const }}[\mathrm{T}]$;

minimum number of obs. in constant head period, $n_{\text {const }}[-]$;

number of noise standard deviations denoting an outlier, $\eta[-]$

\begin{tabular}{l|l}
\hline 1 & Sort hydrograph by date/time in ascending order.
\end{tabular}

$2 \quad$ *Identify implausible observation dates*/

$3 \quad$ For ( $i=$ first to most recent observation)

\begin{tabular}{|l|c|}
\hline 4 & If $\left(t_{i}<t_{\min }\right.$ Or $t_{i}>\min \left(\right.$ Today's date, $\left.\left.t_{\max }\right)\right)$ \\
\hline 5
\end{tabular}

Remove observation $i$.

* Identify duplicate observations for a time point. */

For ( $i$ = first to second most recent observation)

If $\left(\left|t_{i+1}-t_{i}\right|<\operatorname{sqrt}(\right.$ floating point machine precision) $)$

Remove observation $i$.

* Identify implausibly high or low head values. */

For ( $i=$ first to most resent observation)

\begin{tabular}{l|l}
\hline 12 & If $\left(h_{i}<h_{\min }\right.$ Or $\left.h_{i}>h_{\max }\right)$
\end{tabular}

\begin{tabular}{l|l}
13 & Remove observation $i$.
\end{tabular}

$14 \quad$ * Identify implausibly rapid change in the head.*/

$15 \quad$ For ( $i=$ first to second most recent observation)

16

17

18

For ( $i=$ first to second most recent observation)

$r_{i}=\operatorname{abs}\left(\left(h_{i+1}-h_{i}\right) /\left(t_{i+1}-t_{i}\right)\right.$

If $\left(r_{i}>r_{\max }\right)$

isError ${ }_{i}=$ True

* Filter hydrograph to non-erroneous observations.*/

$\boldsymbol{h}=\boldsymbol{h}$ (Not isError)

clear isError

* Identify periods of constant head. First the periods of constant head are identified, then their duration is assessed.*/

\begin{tabular}{|l|l}
\hline 23 & For ( $i=$ first to second most recent observation) \\
\hline 24 &
\end{tabular}

24

25

26

27

28

29 


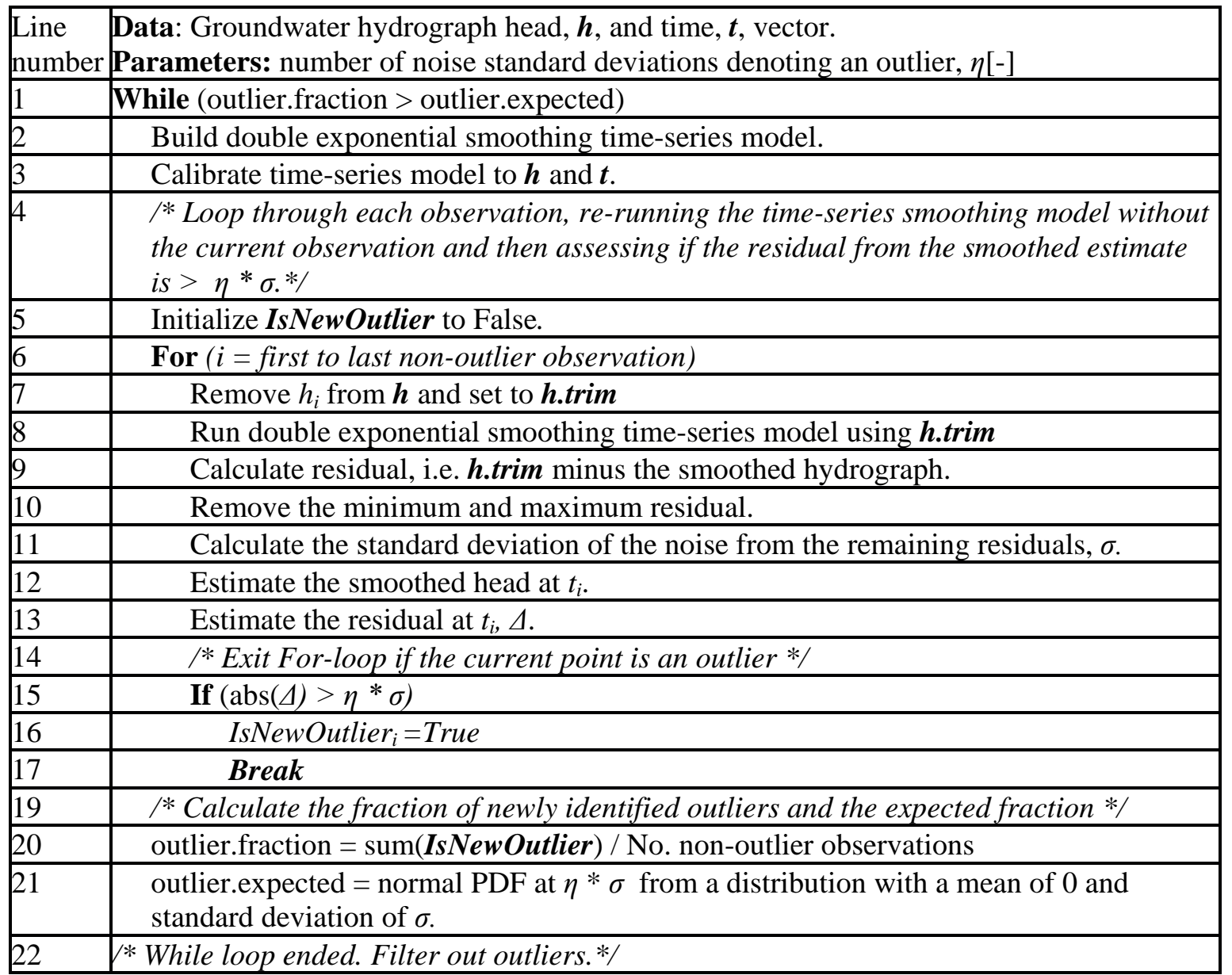



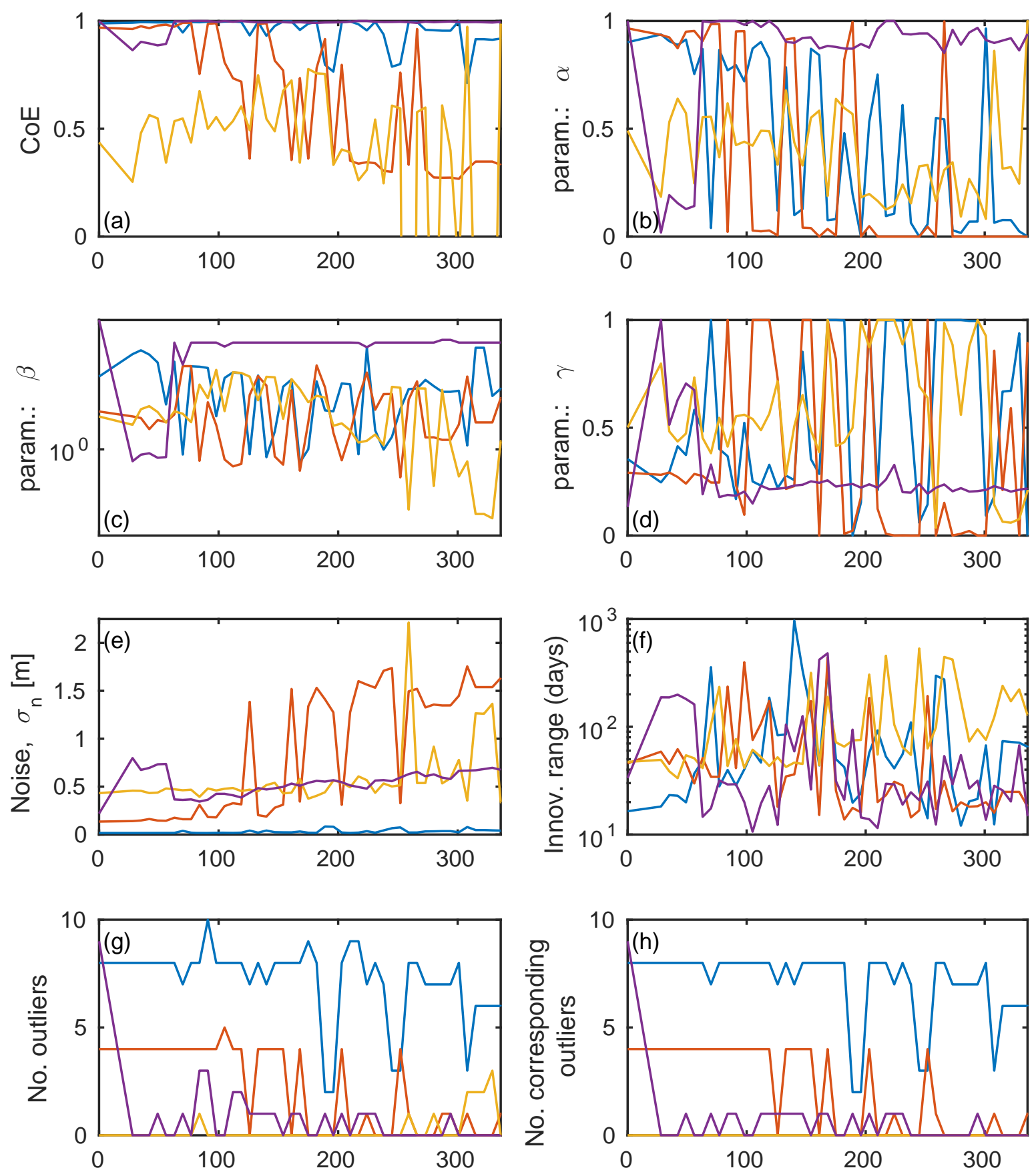

Re-sampled min. obs. time-step

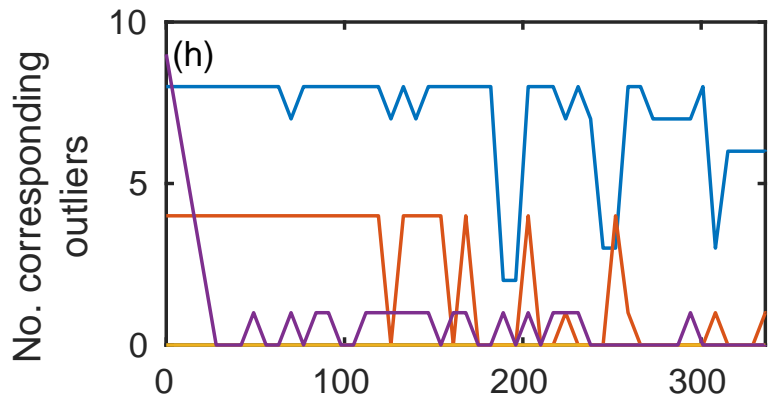

Re-sampled min. obs. time-step

\begin{tabular}{|l}
\hline Bore $27174 \quad$ Bore WRK957283 —— Bore $1101 \quad$ - Bore 99 \\
\hline
\end{tabular}




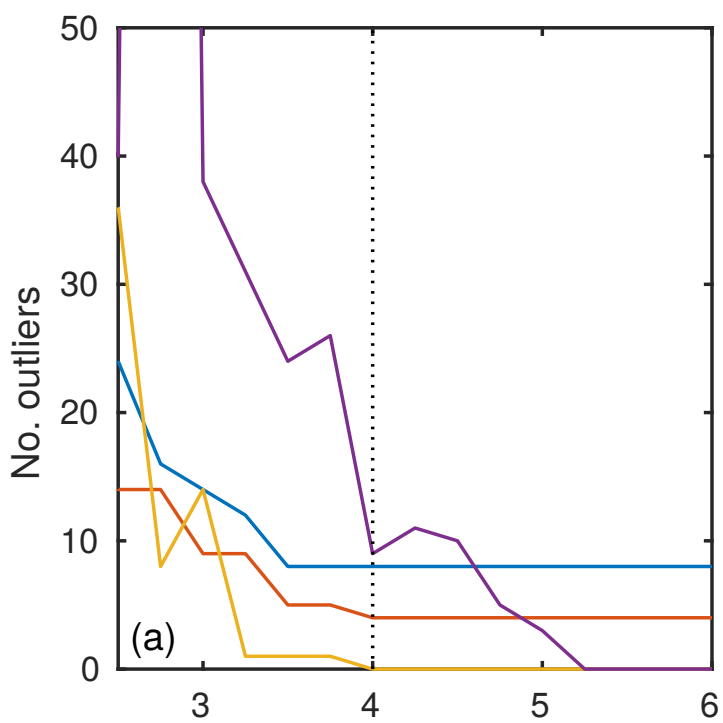

Threshold num. noise std. devs, $\eta$

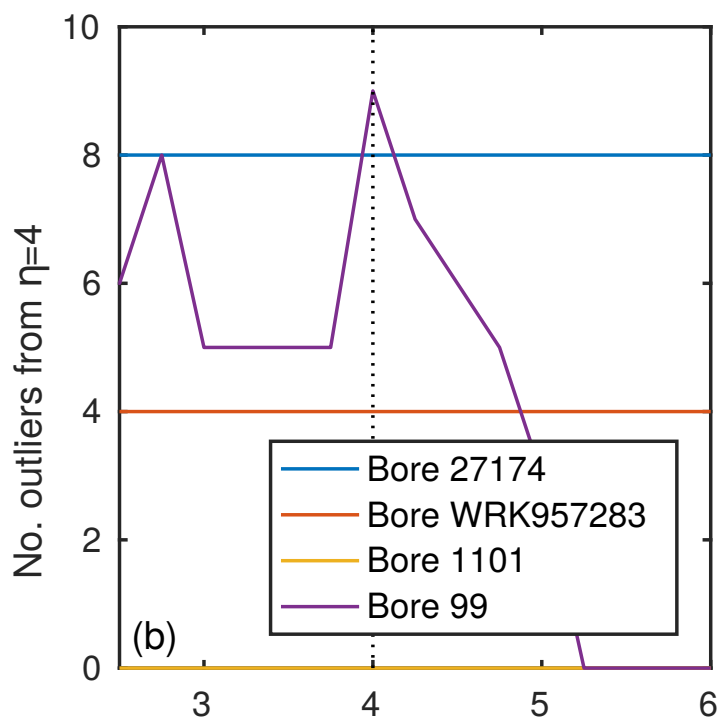

Threshold num. noise std. devs, $\eta$ 


\section{University Library}

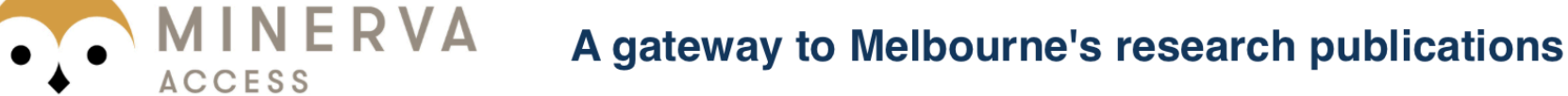

Minerva Access is the Institutional Repository of The University of Melbourne

Author/s:

Peterson, TJ;Western, AW;Cheng, $X$

Title:

The good, the bad and the outliers: automated detection of errors and outliers from groundwater hydrographs

Date:

2018-03-01

Citation:

Peterson, T. J., Western, A. W. \& Cheng, X. (2018). The good, the bad and the outliers: automated detection of errors and outliers from groundwater hydrographs. HYDROGEOLOGY JOURNAL, 26 (2), pp.371-380. https://doi.org/10.1007/ s10040-017-1660-7.

Persistent Link:

http://hdl.handle.net/11343/282626 